\title{
Application of polyaniline nanofibers for the construction of nitrate all-solid-state ion-selective electrodes
}

\author{
Karolina Pietrzak $^{1} \cdot$ Cecylia Wardak ${ }^{1}$ (D) Szymon Malinowski ${ }^{2}$
}

Received: 7 September 2021 / Accepted: 7 November 2021 / Published online: 18 November 2021

(c) The Author(s) 2021

\begin{abstract}
The application of polyaniline nanofibers doped with chloride and nitrate ions (PANINFs-Cl and PANINFs-NO ${ }_{3}$ ) in potentiometry was described. Both kinds of nanofibers were used as an ion-to-electron transducer in ion-selective electrodes with solid contact (SCISEs). Extensive research on the properties of the nanofibers themselves (SEM, UV-Vis spectroscopy, FTIR) and the constructed electrodes (potentiometric methods, electrochemical impedance spectroscopy) has been carried out. Basic analytical parameters of electrodes containing various nanofibers contents in the ion-selective membrane and with nanofibers as an intermediate layer were determined. It was found that application of PANI nanofibers resulted in improvement of electrode performance (among others, better stability and reversibility of the electrode potential). The obtained sensors were characterized by a high slope of the calibration curve, a wide measuring range and a fast response time. Moreover, they were insensitive to change of redox potential, as well as light and the presence of oxygen in the solution, what is important from a practical point of view. They were also successfully used for nitrate determination in real environmental samples.
\end{abstract}

Keywords Ion-selective electrodes $\cdot$ Solid contact $\cdot$ Potentiometry $\cdot$ Nitrate $\cdot$ PANI nanofibers

\section{Introduction}

Thanks to their numerous technical advantages (easy operation of the equipment, speed of analysis, cheap apparatus, no need for special preparation of liquid samples) and analytical ones (very good selectivity, low detection limits) potentiometric methods are still very popular, especially in environmental chemistry (De Marco et al. 2007; Crespo 2017). The most popular sensors used in potentiometric methods are ion-selective electrodes (ISEs). The principle of measurement using them is to measure the electrochemical force of the cell (EMF), which is made of an ion-selective electrode (whose potential depends on the activity of ions in

Cecylia Wardak

cecylia.wardak@mail.umcs.pl

1 Department of Analytical Chemistry, Faculty of Chemistry, Institute of Chemical Sciences, Maria Curie-Sklodowska University, Maria Curie-Sklodowska Sq. 3, 20-031 Lublin, Poland

2 Faculty of Civil Engineering and Architecture, Lublin University of Technology, Nadbystrzycka 40, 20-618 Lublin, Poland the solution) and a reference electrode (whose potential is constant) (Hu et al. 2016).

The first designs of ion-selective electrodes consisted of an inner electrode, an ion-selective membrane and also an internal solution placed between them, which was in direct contact with the membrane and provided the proper charge transfer mechanism between the membrane and the discharge electrode. They showed very good analytical parameters, but due to the presence of the solution inside the electrode the sensors had a relatively large size and their storage and transport were difficult. Air bubbles could have occurred inside such an electrode and moreover, it was necessary to replenish the solution which, when leaking into the sample solution, could cause an artificial increase in the detection limit by triggering an increase in the concentration of the analyte (main ion) in the nearest sample-electrode layer. The solution in this case was to eliminate of internal solution (coated-wire electrodes); however, this was associated with deterioration in the stability and reversibility of the electrode potential as a result of the direct connection of two materials with different conductivity, notably the substrate electrode (electronic conductivity) and the ion-selective membrane (ionic conductivity), thus blocking the flow of charge at the interface (Bobacka 2006). To obtain a satisfactory potential 
stability, at the same time with no internal solution, additional material with mixed conductivity (ion-electron transducer) placed as an intermediate layer between them, was used to construct the electrodes (Michalska 2012). In this way, ion-selective electrodes with solid contact (SCISEs) were created (Bieg et al. 2017). The use of this additive contributed to ensuring the appropriate stability and reversibility of the sensors' potential, facilitated their operation under changing pressure and temperature conditions, and enabled their miniaturization and shape change (Bobacka et al. 2008; Lindner and Gyurcsányi 2009).

The first conductive polymers to be used for this purpose were as follows: poly(pyrrole) (PPy) (Michalska et al. 1994; Sutter et al. 2004), poly(3-octylthiophene) (POT) (Konopka et al. 2004; Chumbimuni-Torres et al. 2006; Rubinova et al. 2007), poly(3,4-ethylenedioxythiophene) (PEDOT) (Bobacka et al. 2001; Vázquez et al. 2002; Ocypa et al. 2006) or polianiline (PANI) (An et al. 2000; Han et al. 2004; Lindfors et al. 2007). The characteristics of the SCISEs in which they are used as ion-electron transducers have improved significantly over the years and they are still widely used for this purpose (Bobacka 2006). Conductive polymers belong to a group of materials with unique electrical, electrochemical and optical properties (Abdolahi et al. 2012). Due to its synthesis simplicity, high environmental stability (Jiang et al. 2018), good redox properties, attractive price and unique chemical structure polyaniline (PANI) is particularly important in designing sensors and biosensors (Ahmed et al. 2021). The PANI can be synthesized by oxidative chemical or electrochemical polymerization (Zhang and Wang 2006) and can exist in three forms with different oxidation states and protonation level: leucoemeraldine, pernigraniline and emeraldine base (Najim and Salim 2017). These forms have different conductivities and only emeraldine base PANI in half oxidation state is conductive (Dan et al. 2009). As is reported in the work by Jiang et al. (2018) nanostructured conductive polymers in the form of nanofibers (Zhang et al. 2021), nanowires (Zhang et al. 2020; Zeng et al. 2021) or nanotubes (Das et al. 2021) are particularly important in the field of chemical sensors. In comparison to globular PANI nanostructured forms exhibit greater sensitivity and faster time due to their higher surface area (Huang and Kaner 2004). The PANI nanostructures with controllable length and diameter can be synthesized using hard-template synthesis method that utilizes pores and/or channels of porous materials, i.e., membranes, zeolites or anodic aluminum oxide. However, removal of the template is relatively difficult, which makes this method unpopular (Zhang and Wang 2006). The soft-template synthesis methods, also known as template-free method or self-assembly method to obtain PANI nanostructures uses various structure-directing molecules i.e., surfactants (Zhang and Manohar 2004), deoxyribonucleic acid (DNA) or polyelectrolytes.
Procedures that do not use any matrix, either hard or soft, are a completely separate group of methods for synthesis of nanostructured polymers. This group of methods includes interfacial, radiolytic, rapid mixing, sonochemical and electrochemical polymerization (Zhang and Wang 2006).

This study described the properties of synthesized polyaniline (PANI) nanofibers doped with chloride (PANINFs$\mathrm{Cl}$ ) and nitrate (PANINFs- $\mathrm{NO}_{3}$ ) ions and their use as solid contact in ion-selective electrodes sensitive to nitrate ions. The synthesized nanofibers were characterized using SEM, UV-Vis and FTIR spectrophotometry. They were then used in two ways: as an intermediate layer between the inner glassy carbon electrode and the ion-selective membrane, and as the ion-selective membrane component. The basic analytical parameters of the constructed sensors were examined in order to investigate the influence of PANI nanofibers on their performance. On the basis of potentiometric measurements, information was obtained about the slope of the electrode characteristic curve, their linearity range and the limit of detection, as well as the stability and reversibility of the potential. In addition, research was conducted to investigate the influence of variable conditions on the proper operation of the sensors (the effect of changes in solution $\mathrm{pH}$ and redox potential, the presence of light and oxygen) were carried out. Electrochemical impedance spectroscopy (EIS) was used to determine and compare the electrical parameters of the electrodes, whose values could have changed after the modification of the sensors.

\section{Materials and methods}

\section{Apparatus}

To carry out research enabling the characterization of the obtained structures (PANINFs- $\mathrm{Cl}$ and PANINFs- $\mathrm{NO}_{3}$ ), their solutions with a concentration of $1 \mathrm{mg} \mathrm{mL}^{-1}$ in THF were prepared. The images of PANINFs structure were recorded using a high-resolution scanning electron microscope Quanta 3D FEG (FEI Hillsboro, USA). Ultraviolet-visible spectra (UV-Vis) were recorded on Helios Gamma (Thermo Scientific) ultraviolet-visible spectrometer in wavelength ranged from 200 to $900 \mathrm{~nm}$. FT-IR/DRS spectra were collected using a Nicolet 380 spectrophotometer purchased from Thermo Scientific. The spectra of PANI nanostructures obtained in presence of $\mathrm{Cl}^{-}$and $\mathrm{NO}_{3}{ }^{-}$ions were recorded in range of $4000-400 \mathrm{~cm}^{-1}$ with resolution of $4 \mathrm{~cm}^{-1}$ at room temperature. To guarantee good signal/noise ratio, the spectra were consisted of 2048 scans.

Potentiometric measurements were performed for a cell which consisted of the tested ion-selective electrodes and the $\mathrm{Ag} / \mathrm{AgCl}$ reference electrode (Metrohm 6.0750.100). The electrodes were immersed in solutions of the main ion 
salt $\left(\mathrm{KNO}_{3}\right)$ mixed with a magnetic stirrer. A potentiometer (Lawson Labs, Inc.) coupled to a computer was used to obtain and collect data. Additionally, an ORION 81-72 glass electrode and an Elmetron CX-741 potentiometer were used to determine the $\mathrm{pH}$ of the solutions. All measurements were made at room temperature.

Measurements obtained by the electrochemical impedance spectroscopy (EIS) were performed in a $1 \times 10^{-2} \mathrm{~mol}$ $\mathrm{L}^{-1} \mathrm{KNO}_{3}$ solution. The system included three kinds of electrodes: our tested ISE as working electrode, $\mathrm{Ag} / \mathrm{AgCl}$ reference electrode (Metrohm 6.0733.100) and the auxiliary electrode-a GC rod $2 \mathrm{~mm} / 65 \mathrm{~mm}$ (Metrohm). As the measuring device the AUTOLAB electrochemical analyzer (Eco Chemie, Netherlands) controlled by NOVA software. The impedance spectra were recorded in the frequency range $0.1-100 \mathrm{kHz}$ at the open circuit potential with an amplitude $10 \mathrm{mV}$.

\section{Reagents}

Substances necessary for the synthesis of aniline nanofibers: aniline monomer, ammonium peroxydisulfate (APS), hydrochloric acid, nitric acid, tetrahydrofuran (THF) were purchased from Chempur.

Ion-selective membrane components for electrodes construction: $o$-nitrophenyl octyl ether (NPOE), low molecular weight poly(vinylchloride) (PVC), tridodecyl dimethyl ammonium nitrate $\left(\mathrm{TDMANO}_{3}\right)$ were purchased from Aldrich. Salts for the preparation of solutions with different redox potential were obtained from Alfa Aesar $\left(\mathrm{Na}_{4} \mathrm{Fe}(\mathrm{CN})_{6} \times 10 \mathrm{H}_{2} \mathrm{O}\right)$ and from POCh-Polish Chemical Reagents $\left(\mathrm{K}_{3} \mathrm{Fe}(\mathrm{CN})_{6}\right)$. The remaining substances, including potassium salts for testing the selectivity of sensors, sulfuric acid and sodium base for changes of $\mathrm{pH}$ of the solutions, were obtained from Fluka. Compounds of the highest purity and freshly redistilled water were used to prepare all solutions.

\section{PANI nanofibers synthesis}

PANI nanofibers were synthesized by interfacial polymerization according to procedure described in paper (Huang and Kaner 2004) and shown in Fig. 1. A 50 mmol amount of aniline monomer was dissolved in mixture of $\mathrm{EtOH}$ and distillated water to obtain solution with concentration of $5 \times 10^{-2} \mathrm{~mol}$ $\mathrm{L}^{-1}$. Then, in two separate vials, $0.08 \mathrm{mmol}$ of APS was dissolved in $1 \mathrm{~mol} \mathrm{~L}^{-1} \mathrm{HCl}$ and $\mathrm{HNO}_{3}$ solution, respectively. To carry out the polymerization reaction, the aniline monomer and oxidant solutions were carefully transferred to a beaker to form static interface of two phases: organic phase and water phase. After $12 \mathrm{~h}$ the resulting precipitate was filtered and cleaned using deionized water several times. Directly before using, the synthesized PANI nanofibers were dried at $60{ }^{\circ} \mathrm{C}$ for $24 \mathrm{~h}$.

\section{Preparation of the ion-selective membrane}

To prepare every membrane mixture, all their components were weighed out on an analytical balance in accordance with the previously calculated mass values, and then the dry ingredients were combined with an organic solvent (THF) and homogenized for half an hour in an ultrasonic water bath until a homogeneous mixtures were obtained. $1 \mathrm{ml}$ of solvent was added per $0.1 \mathrm{~g}$ of ingredients. In the case of both types of nanofibers, 4 types of membrane mixtures were prepared: basic mixture (62\% NPOE, 32\% PVC, 6\% $\mathrm{TDMANO}_{3}$ ); I mixture $\left(61.5 \%\right.$ NPOE, $32 \%$ PVC, $6 \%$ TDMANO $_{3}, 0.5 \%$ nanofibers); II mixture (61\% NPOE, 32\% PVC, 6\% $\mathrm{TDMANO}_{3}$, $1 \%$ nanofibers); III mixture (60\% NPOE, 32\% PVC, $6 \%$ $\mathrm{TDMANO}_{3}, 2 \%$ nanofibers).

\section{Preparation of all-solid-state ion-selective electrodes}

Glassy carbon electrodes (GCE) $(0.3 \mathrm{~cm}$ diameter) were polished thoroughly with 5000 grit sandpaper and then polished with wetted alumina powder $(0.3 \mu \mathrm{m}$ grain diameter). The electrodes were rinsed thoroughly with distilled water, immersed in water in an ultrasonic bath, and rinsed again with distilled water to remove dust residues. To get rid of organic residues, the electrodes were immersed in THF and allowed to dry in a stand. For both types of nanofibers, 5 types of electrodes were made: unmodified electrodes containing only the basic mixture without nanofibers-GCE/ISM, electrodes with $0.5 ; 1.0$ and $2 \%$ nanofibers in the ion-selective membrane (GCE/(ISM + 0.5\%PANINFs-Cl); GCE/(ISM + 1.0\%PANINFs-Cl) and GCE/(ISM + 2.0\%PANINFs-Cl) for PANI-Cl nanofibers and $\mathrm{GCE} /\left(\mathrm{ISM}+0.5 \% \mathrm{PANINFs}-\mathrm{NO}_{3}\right)$; GCE/ (ISM+ 1.0\%PANINFs-NO ${ }_{3}$ ) and GCE/(ISM+2.0\%PANINFs$\mathrm{NO}_{3}$ ) for PANI-NO $\mathrm{N}_{3}$ nanofibers, respectively) and electrodes with an intermediate layer of nanofibers $(15 \mu \mathrm{l}$ of $0.01 \mathrm{~g} / \mathrm{ml}$ nanofibers in THF) - GCE/PANINFs-Cl/ISM and GCE/PANINFs- $\mathrm{NO}_{3} / \mathrm{ISM}$. On the dry surfaces of the electrodes, 3 times $50 \mu \mathrm{l}$ of membrane mixtures were spotted with an interval of $30 \mathrm{~min}$. The electrodes were then allowed to dry overnight and the next day immersed in a conditioning solution of $\mathrm{KNO}_{3}$ salt at a concentration of $1 \times 10^{-3} \mathrm{~mol} \mathrm{~L}^{-1}$. Between measurements all electrodes were stored in separate containers, immersed in the conditioning solution, closed in a dark place. 


\section{PANI-Cl synthesis}

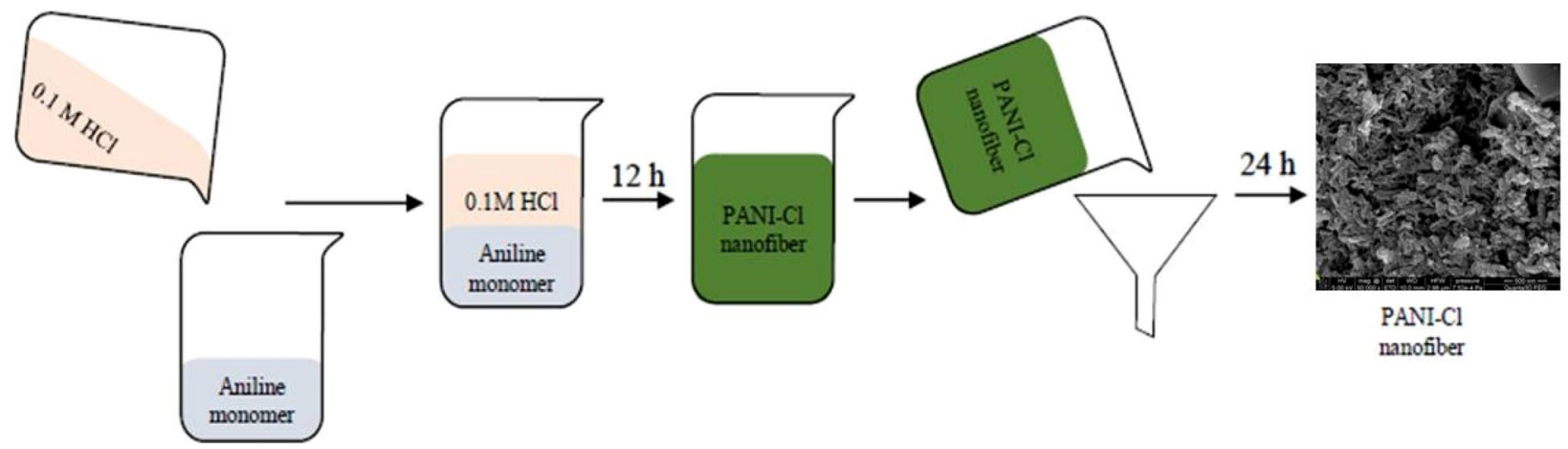

PANI- $\mathrm{NO}_{3}$ synthesis
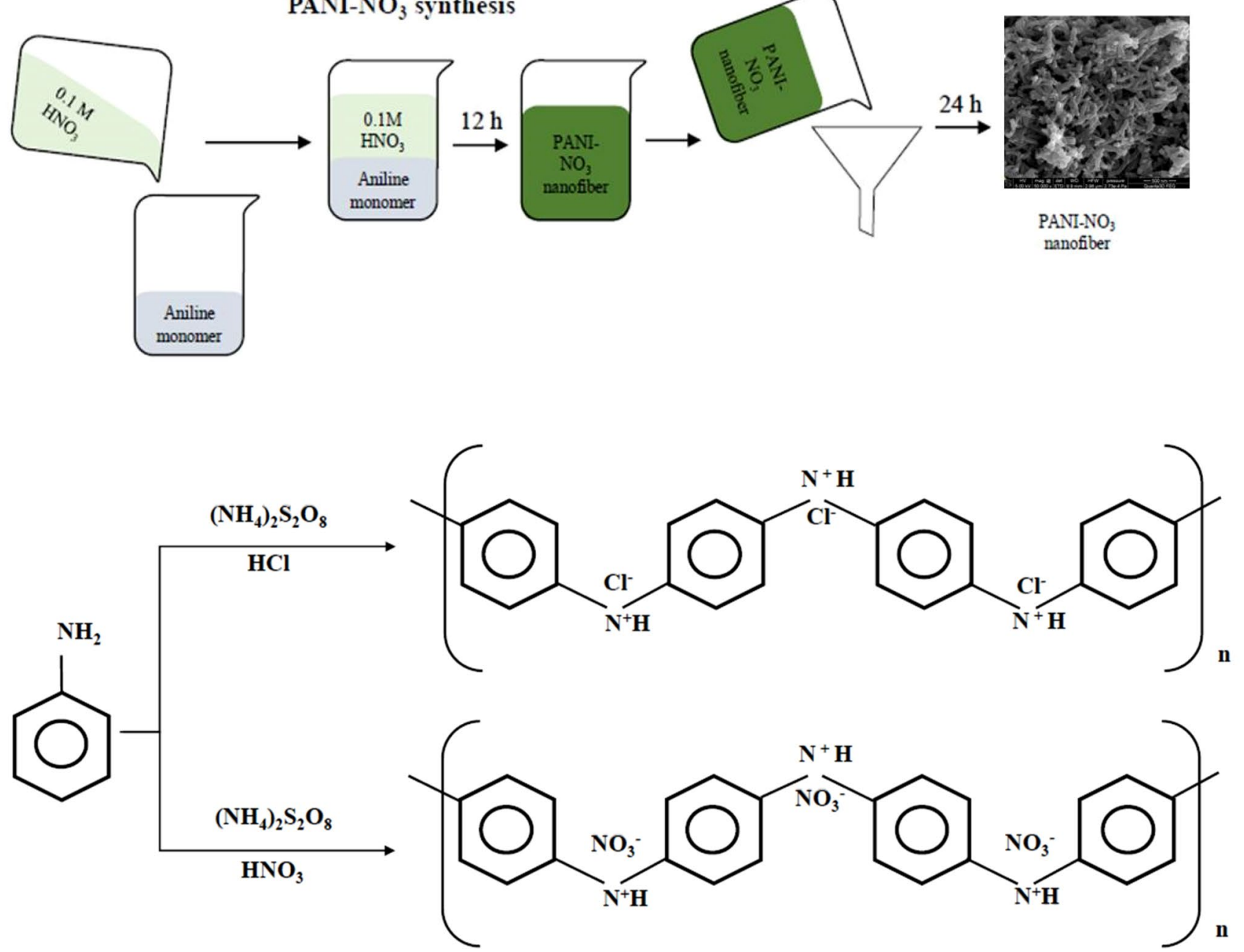

Fig. 1 Procedure for the synthesis of polyaniline nanofibers (PANINFs- $\mathrm{Cl}$ and $\mathrm{PANINFs}-\mathrm{NO}_{3}$ ) and equation of the occurring chemical reaction

\section{Results and discussion}

Modified polyaniline nanofibers were used for the construction of the electrodes as a solid contact placed both as an intermediate layer between the glassy carbon electrode
(GCE) material and the ion-selective membrane material, and as a component of the membrane with different contents. A series of potentiometric measurements were performed to determine the parameters of the electrodes. The slopes of the calibration curves, their linearity ranges and the limits of 
detection were determined for all types of sensors. In addition, the reversibility and stability of the electrode potential were also investigated. The $\mathrm{pH}$ range in which the sensors can work properly and their selectivity for interfering ions were determined. The sensitivity tests of sensors to changing measurement conditions (redox potential change, presence of oxygen and light) were performed. For a more complete analysis, using the electrochemical impedance spectroscopy (EIS) technique, the electrical parameters of the obtained electrodes were also determined and compared.

\section{PANI nanofibers characterization}

The scanning electron micrographs shown in Fig. 2 clearly confirm the preparation of PANI in the form of nanofibers embedded in compact polymeric structures. Structural analysis indicates that the applied ion directly affects the microstructure of the obtained nanofibers, as also observed in the paper (Bednarczyk et al. 2021). The oxidative polymerization reaction carried out in the presence of $\mathrm{NO}_{3}{ }^{-}$ions allows the synthesis of longer and better formed nanofibers. However, the presence of both studied ions results in relatively cohesive structures of polymeric PANI nanofibers. Compact PANI structures may be formed due to the synthesis method, the reaction system oxidizability and the monomer concentration in the reaction system. Applied to PANI nanofibers synthesis interfacial polymerization belongs to static methods where the system is not continuously stirred during the chemical reaction. Secondly, obtaining of compact PANI nanofibers structure may also result from the high oxidizability of the reaction system (Zeng et al. 2015). APS is a relatively strong oxidant, so during the initial stage of the aniline polymerization reaction, a large number of oligomers are probably formed, and their further combination led to the compact nanofiber structure. In addition, the compact nanofiber structure may be due to the high monomer
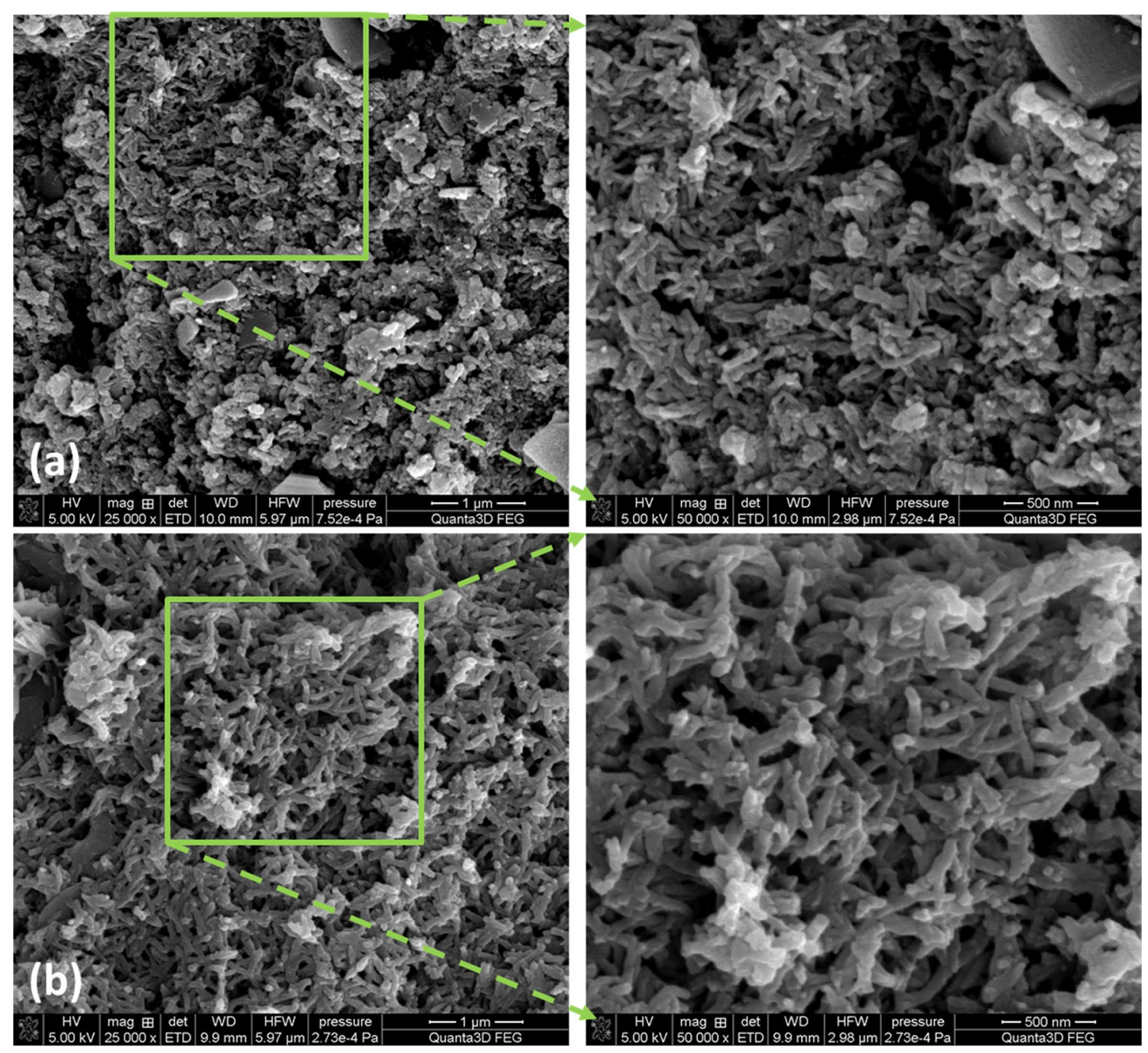

Fig. 2 SEM images of PANINFs-Cl (a) and PANINFs- $\mathrm{NO}_{3}$ (b)

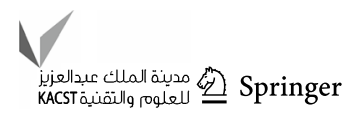


concentration, which causes subsequent nanofibers to be deposited on previously synthesized polymers.

Figure 3 shows the UV-Vis spectrum of PANI nanofibers synthesized in the presence of $\mathrm{Cl}^{-}$and $\mathrm{NO}_{3}{ }^{-}$ions. These spectra show three main absorption bands with different intensities depending on the ion employed. This means that the type of used ion does not significantly influence the optical structure of the obtained PANI nanofibers. Both PANI nanofibers contain a cation radical in their structure, as indicated by the presence of absorption bands at $238 \mathrm{~nm}$ (PANINFs-Cl) and $232 \mathrm{~nm}$ (PANINFs-NO ${ }_{3}$ ) corresponded to $\pi-\pi^{*}$ transition in benzenoid structure (Zeng et al. 2015; El-ghaffar et al. 2016). The absorption bands appearing at wavelengths above $300 \mathrm{~nm}$ correspond to polar on band $\rightarrow \pi^{*}$ transition indicating that both PANINFs-Cl and PANINFs- $\mathrm{NO}_{3}$ are partially doped (Zhang et al. 2009). These characteristic peaks clearly confirm synthesis of conductive emeraldine salt form.

Figure 4 shows the FTIR spectra of PANI nanofibers synthesized in the presence of $\mathrm{Cl}^{-}$and $\mathrm{NO}_{3}{ }^{-}$ions. Analysis indicates that the type of ion used does not affect the molecular



Fig. 3 UV-Vis spectrum of PANI nanofibers synthesized in the presence of $\mathrm{Cl}^{-}$(blue line) and $\mathrm{NO}_{3}^{-}$(orange line) ions structure of the synthesized fibers either. The FTIR spectra obtained indicate the presence of bands characteristic for PANI. The broad band appearing at a wavelength of about $3500 \mathrm{~cm}^{-1}$ is attributed to $-\mathrm{NH}_{2}$ stretching. At wavelengths of about $3200 \mathrm{~cm}^{-1}$ and $2850 \mathrm{~cm}^{-1}$ two small peaks attributed, respectively to $-\mathrm{N}-\mathrm{H}^{+}$and $\mathrm{C}-\mathrm{H}$ bonds vibrations are observed. The existence of a protonated amine group is also confirmed by peaks at about $1630 \mathrm{~cm}^{-1}$ and $1090 \mathrm{~cm}^{-1}$ assigned to $-\mathrm{N}-\mathrm{H}$ and $\mathrm{C}-\mathrm{NH}^{+} \bullet-\mathrm{C}$ vibrations, respectively. The vibration of the $\mathrm{C}-\mathrm{NH}+\bullet-\mathrm{C}$ group and $-\mathrm{N}-\mathrm{H}^{+}$bond clearly confirm that the synthesis of PANI in both the presence of $\mathrm{Cl}^{-}$and $\mathrm{NO}_{3}{ }^{-}$ions leads to the formation of a nanostructured polymer in salt form. The benzenoid structure of obtained PANI nanostructures is confirmed by peaks at $1450 \mathrm{~cm}^{-1}, 1200 \mathrm{~cm}^{-1}$ and $880 \mathrm{~cm}^{-1}$ corresponding, respectively to $\mathrm{C}-\mathrm{C}$ bond stretching vibration, $\mathrm{C}-\mathrm{C}-\mathrm{H}$ group vibration and out-of-plane bending vibration of $\mathrm{C}-\mathrm{H}$ bond (Zhang et al. 2009; Zeng et al. 2015; Ahmed et al. 2021).

\section{Potentiometric response}

The dependence of the potential of the tested electrodes on nitrate ions concentration was measured in $\mathrm{KNO}_{3}$ solutions in the concentration range of $1 \times 10^{-7}-1 \times 10^{-1} \mathrm{~mol} \mathrm{~L}^{-1}$ in relation to the silver chloride electrode as the reference electrode. The obtained calibration curves for all electrodes are shown in the Fig. 5. The slopes of the calibration curves obtained by these measurements, their linearity ranges and detection limits are summarized in Table 1.

As it can be seen in Fig. 5 and Table 1 use of PANINFs to the nitrate ion-selective electrodes preparation had the beneficial effect on their potentiometric response. In each case, the modified electrode showed a wider measuring range, a lower limit of detection and a greater slope of the calibration curve than the electrode without nanofibers. Considering
Fig. 4 FTIR spectra of PANI nanofibers synthesized in the presence of $\mathrm{Cl}^{-}$(black line) and $\mathrm{NO}_{3}^{-}$(orange line) ions

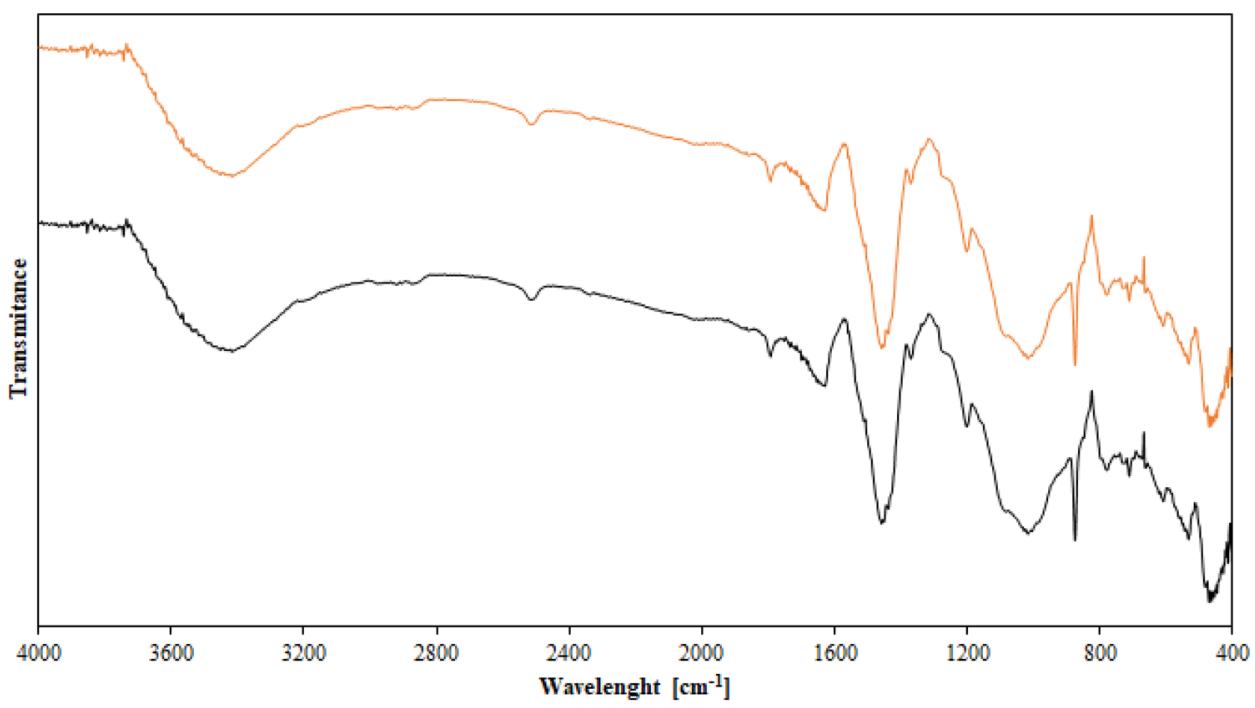



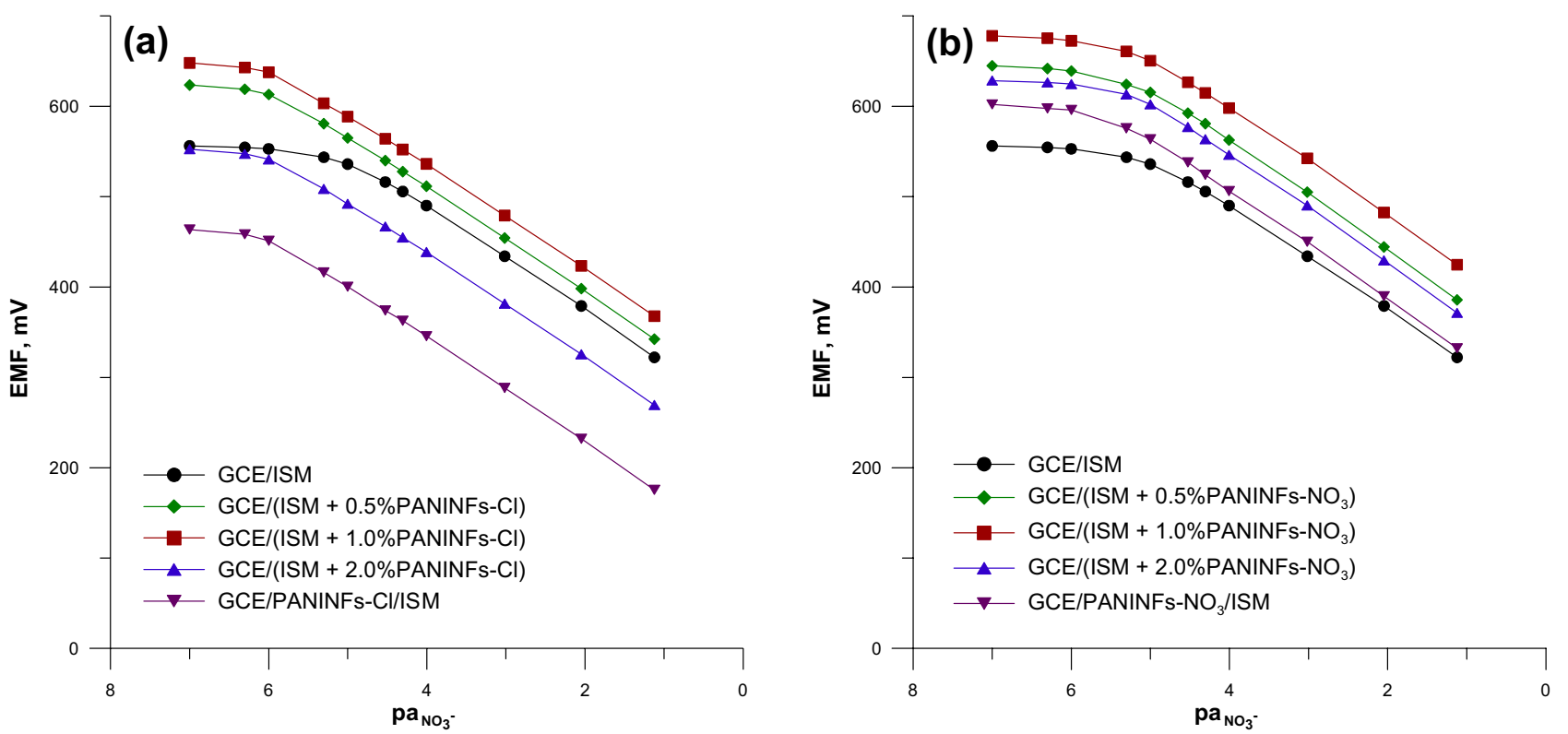

Fig. 5 Calibration curves of the electrodes with: a PANINFs-Cl, b PANINFs- $\mathrm{NO}_{3}$ determined in the $\mathrm{KNO}_{3}$ solution in the concentration range of $1 \times 10^{-7}-1 \times 10^{-1} \mathrm{~mol} \mathrm{~L}^{-1}$

Table 1 Selected analytical parameters obtained for the tested electrodes

\begin{tabular}{|c|c|c|c|c|c|c|c|}
\hline \multirow[t]{2}{*}{ Electrode } & \multirow[t]{2}{*}{$\begin{array}{l}\text { Slope } \\
{[\mathrm{mV} / \mathrm{dec}-} \\
\text { ade }]\end{array}$} & \multirow[t]{2}{*}{$\begin{array}{l}\text { Limit of } \\
\text { detection [mol } \\
\left.\mathrm{L}^{-1}\right]\end{array}$} & \multirow[t]{2}{*}{ Linear range $\left[\mathrm{mol} \mathrm{L}^{-1}\right]$} & \multirow[t]{2}{*}{$\begin{array}{l}\text { Short term } \\
\text { potential drift } \\
{[\mathrm{mV} / \mathrm{h}]}\end{array}$} & \multicolumn{2}{|c|}{$\begin{array}{l}\text { Reversibility (in } \\
1 \times 10^{-4} \mathrm{~mol} \mathrm{~L}^{-1} \text { solu- } \\
\text { tion) }\end{array}$} & \multirow[t]{2}{*}{$\mathrm{pH}$ range } \\
\hline & & & & & Mean $[\mathrm{mV}]$ & $\mathrm{SD}[\mathrm{mV}]$ & \\
\hline GCE/ISM & 55.75 & $3.98 \times 10^{-6}$ & $1 \times 10^{-5}-1 \times 10^{-1}$ & 4.74 & 486.13 & 2.43 & $4.0-11.0$ \\
\hline $\mathrm{GCE} /(\mathrm{ISM}+0.5 \%$ PANINFs-Cl) & 56.07 & $3.47 \times 10^{-7}$ & $1 \times 10^{-6}-1 \times 10^{-1}$ & 1.08 & 512.35 & 0.45 & $4.0-12.5$ \\
\hline $\mathrm{GCE} /(\mathrm{ISM}+1.0 \% \mathrm{PANINFs}-\mathrm{Cl})$ & 56.67 & $3.39 \times 10^{-7}$ & $1 \times 10^{-6}-1 \times 10^{-1}$ & 1.02 & 537.52 & 0.52 & $4.0-12.5$ \\
\hline GCE/(ISM + 2.0\%PANINFs-Cl) & 56.17 & $3.55 \times 10^{-7}$ & $1 \times 10^{-6}-1 \times 10^{-1}$ & 1.26 & 439.92 & 0.51 & $4.0-12.5$ \\
\hline GCE/PANINFs-Cl/ISM & 56.78 & $3.16 \times 10^{-7}$ & $1 \times 10^{-6}-1 \times 10^{-1}$ & 0.53 & 346.35 & 0.33 & $4.0-12.5$ \\
\hline $\mathrm{GCE} /\left(\mathrm{ISM}+0.5 \%\right.$ PANINFs-NO $\left.\mathrm{N}_{3}\right)$ & 57.20 & $1.58 \times 10^{-6}$ & $5 \times 10^{-6}-1 \times 10^{-1}$ & 1.04 & 562.91 & 0.48 & $4.0-11.5$ \\
\hline $\mathrm{GCE} /\left(\mathrm{ISM}+1.0 \%\right.$ PANINFs-NO $\left.\mathrm{N}_{3}\right)$ & 57.22 & $1.41 \times 10^{-6}$ & $5 \times 10^{-6}-1 \times 10^{-1}$ & 1.12 & 596.85 & 0.29 & $4.0-11.5$ \\
\hline $\mathrm{GCE} /\left(\mathrm{ISM}+2.0 \%\right.$ PANINFs-NO $\left.\mathrm{N}_{3}\right)$ & 57.50 & $1.51 \times 10^{-6}$ & $5 \times 10^{-6}-1 \times 10^{-1}$ & 1.13 & 545.70 & 0.36 & $4.0-11.5$ \\
\hline GCE/PANINFs- $\mathrm{NO}_{3} / \mathrm{ISM}$ & 57.80 & $1.12 \times 10^{-6}$ & $5 \times 10^{-6}-1 \times 10^{-1}$ & 0.84 & 504.43 & 0.14 & $4.0-11.5$ \\
\hline
\end{tabular}

Short term potential drift value_-given in absolute values

both types of nanofibers used, it can be seen that PANI-Cl nanofibers have a greater influence on the improvement of electrode's analytical parameters. The electrodes containing them both in the membrane and as an intermediate layer show wider linearity range of $1 \times 10^{-6}-1 \times 10^{-1} \mathrm{~mol} \mathrm{~L}^{-1}$ and also achieved lower limits of detection than other electrodes. The lowest limit of detection of $3.16 \times 10^{-7} \mathrm{~mol} \mathrm{~L}^{-1}$ was obtained for the GCE/PANINFs-Cl/ISM). In the case of electrodes containing PANINFs- $\mathrm{NO}_{3}$ in the membrane also, an improvement in the electrode response was observed compared to the unmodified electrode, but to a lesser degree. For these electrodes the detection limit decreased by about
0.5 orders of magnitude. However, for the electrode based on PANINFs- $\mathrm{NO}_{3}$ as an intermediate layer, similar results were obtained as for electrodes based on PANINFs-Cl.

\section{Potential reversibility}

The reversibility of the electrode potential was tested in the $\mathrm{KNO}_{3}$ solution with concentrations of $1 \times 10^{-4}$ and $1 \times 10^{-3} \mathrm{~mol} \mathrm{~L}^{-1}$. The obtained results are shown in Fig. 6 . The electrodes modified with both PANI-Cl and PANI-NO nanofibers show a noticeably more stable potential compared to the unmodified electrode. The average potentials 

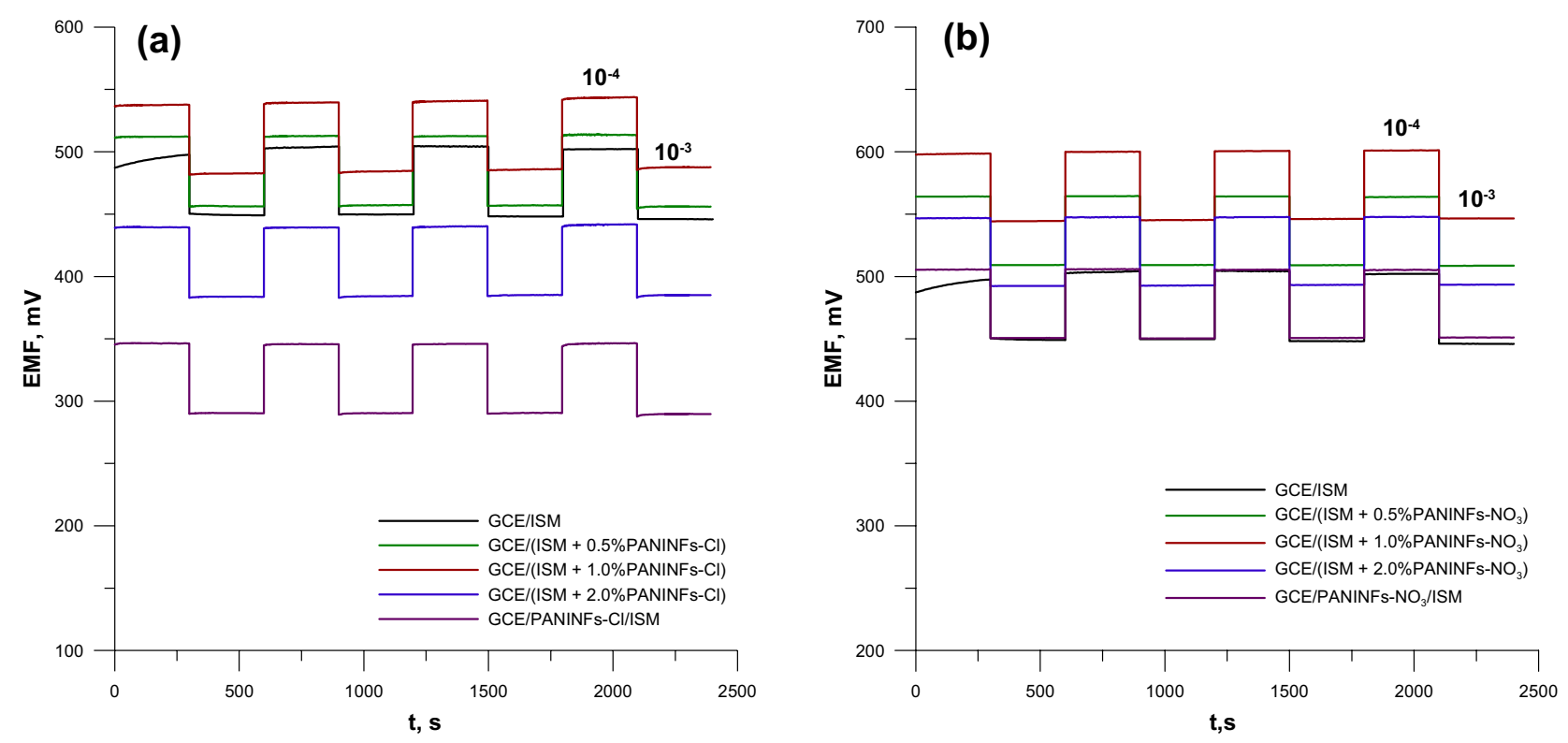

Fig. 6 Reversibility of the electrodes response: a PANINFs-Cl, b PANINFs- $\mathrm{NO}_{3}$

and standard deviations obtained for 4 measurements in a solution of the main ion with a concentration of $1 \times 10^{-4} \mathrm{~mol}$ $\mathrm{L}^{-1}$ are summarized in the Table 1 . The electrodes were stable and gave a fast response after changing the solution concentration. Except for the unmodified electrode (GCE/ ISM), for which the calculated SD for a results obtained in a solution with a concentration of $1 \times 10^{-4} \mathrm{~mol} \mathrm{~L}^{-1}$ was $2.43 \mathrm{mV}$, for all other modified electrodes SD was more than two times smaller $<1 \mathrm{mV}$.

\section{Short-term stability of the potential}

The short-term stability of the electrode potential was measured in a $\mathrm{KNO}_{3}$ solution with a concentration of $1 \times 10^{-1} \mathrm{~mol}$ $\mathrm{L}^{-1}$. Figure 7 shows the potential change that occurred in the solution during $3 \mathrm{~h}$ (time selected as optimal, during which it is possible to successfully perform calibration and series of measurements with reserve). The addition of nanofibers both to the membrane and as an intermediate layer had a good effect on improving the stability of the sensors, the stability of which was significantly improved compared to the unmodified electrode $(4.74 \mathrm{mV} / \mathrm{h}$ ) (Table 1$)$. Among the modified electrodes, the electrodes with the intermediate layer of PANI-Cl and PANI-NO ${ }_{3}$ nanofibers were characterized by a lower potential drift of 0.53 and $0.84 \mathrm{mV} / \mathrm{h}$, respectively.

\section{pH range}

Measurements of the electrode potential were also performed in solutions of various $\mathrm{pH}$, with the main $\mathrm{NO}_{3}{ }^{-}$ion concentration equal to $1 \times 10^{-3} \mathrm{~mol} \mathrm{~L}^{-1}$. The $\mathrm{pH}$ range at which the potential was constant was very broad for all electrodes, while for the PANINFs-Cl based electrodes the $\mathrm{pH}$ range was somewhat wider in the alkaline range. Measurements with these electrodes can be successfully performed even in the range of $\mathrm{pH} 4.0-12.5$ (Table 1). It is a very wide $\mathrm{pH}$ range, which does not significantly limit the possibility of determining nitrate ions in liquid samples.

\section{Selectivity}

The selectivity of ion-selective electrodes is a very important analytical parameter, necessary for their proper operation and obtaining correct analysis results. The good selectivity of the sensors allows to determine the concentration of the analyte (main ion) in the presence of other ions present in the solution. The components of the ion-selective membrane are responsible for selectivity, the most important of which is the ionophore, but also other ionic additions. The selectivity of the obtained sensors was tested using the separate solutions method (SSM) (Bakker et al. 2000). The addition of PANINFs did not significantly change the selectivity of the sensors. However, in all cases the selectivity also did not deteriorate. A greater difference in improved selectivity coefficients was noted for electrodes with nanofibers in the membrane than for electrodes with an intermediate layer. The results obtained for electrodes based on PANINFs-Cl nanofibers are shown in the Fig. 8. The selectivity coefficients for PANINFs$\mathrm{NO}_{3}$ electrodes were determined with the same method. 

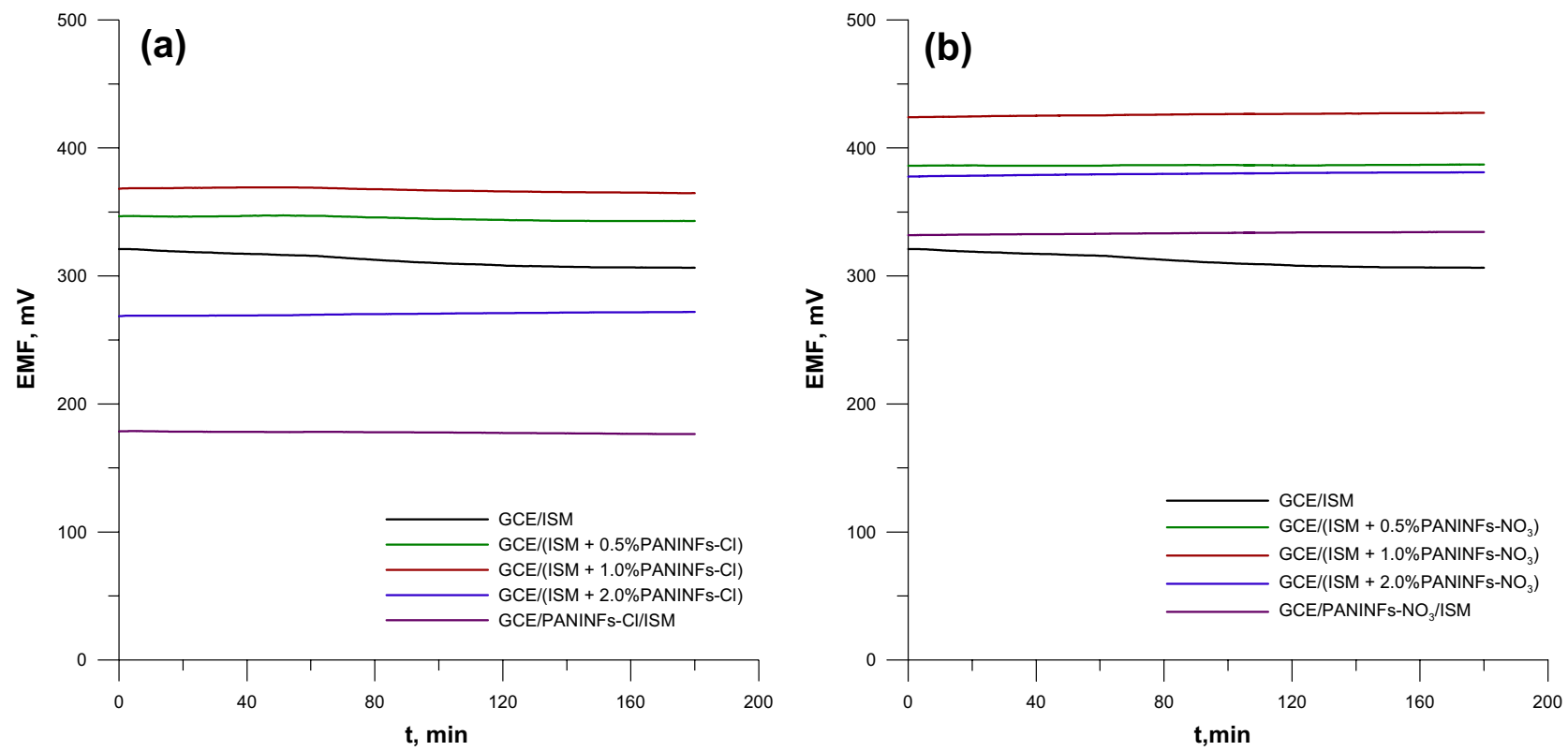

Fig. 7 Time dependence of the potential in a $\mathrm{KNO}_{3}$ solution with a concentration of $1 \times 10^{-1}$ mol L ${ }^{-1}$ for the a PANINFs-Cl, b PANINFs-NO electrodes

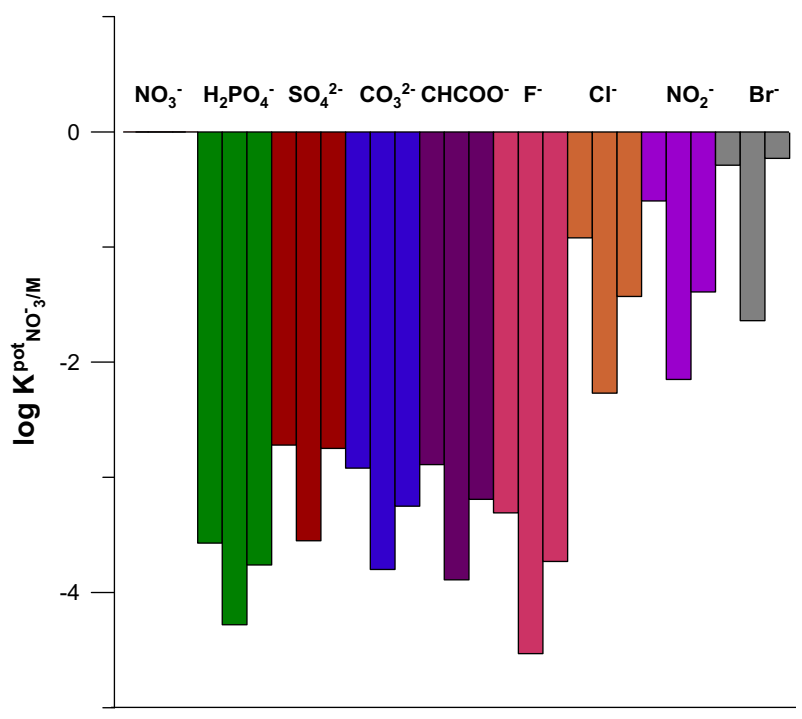

Fig. 8 Comparison of selectivity coefficients values for the studied sensors: GCE/ISM (1st column); GCE/(ISM+1.0\%PANINFs-Cl) (2nd column) and GCE/PANINFs-Cl/ISM (3rd column)

The obtained values were comparable to those obtained for the electrodes with PANINFs-Cl.

\section{Effects of light and $\mathrm{O}_{2}$}

The resistance of the electrodes to changes in measurement conditions is very important to ensure the correctness of the obtained results. Electrodes containing conductive polymers as solid contact, unfortunately, are often sensitive to light, the presence of gases $\left(\mathrm{CO}_{2}, \mathrm{O}_{2}\right)$ and $\mathrm{pH}$ changes, therefore it is very important to check whether the sensors are able to work properly regardless of external conditions (Vázquez et al. 2002). The research on the influence of light and the presence of oxygen in solutions on the electrode potential was performed. The potential measurements were made in the $\mathrm{KNO}_{3}$ solution with a concentration of $1 \times 10^{-1} \mathrm{~mol} \mathrm{~L}^{-1}$. The dependence of the electrode potential with the light on and off is shown in Fig. 9, while in a deoxygenated and containing oxygen solution, in Fig. 10. The solution was deoxygenated by bubbling nitrogen through it for half an hour. All sensors worked properly, regardless of exposure to light and different oxygen content in the solution. The value of the potential does not change significantly, so it can be concluded that they are not sensitive to changes of these parameters.

\section{Redox sensitivity}

Redox sensitivity measurements were performed in solutions containing a pair of redox ions $\mathrm{Fe}^{2+}$ and $\mathrm{Fe}^{3+}\left(\mathrm{Na}_{4} \mathrm{Fe}(\mathrm{CN})_{6}\right.$ and $\left.\mathrm{K}_{3} \mathrm{Fe}(\mathrm{CN})_{6}\right)$ in the constant ionic background of $1 \times 10^{-3} \mathrm{~mol} \mathrm{~L}^{-1} \mathrm{KNO}_{3}$. The $\log \mathrm{Fe}^{2+} / \mathrm{Fe}^{3+}$ ratio was -1 ; $-0.7 ; 0 ; 0.7$ and 1 . Figure 11 shows the dependence of the measured potential on the value of the redox potential of the solution. For all electrodes, the change of redox potential does not impact on the electrode potential, which was almost constant $\left(\mathrm{sd}_{\max } \pm 1.37 \mathrm{mV}\right)$ in all solutions. Therefore, it can 


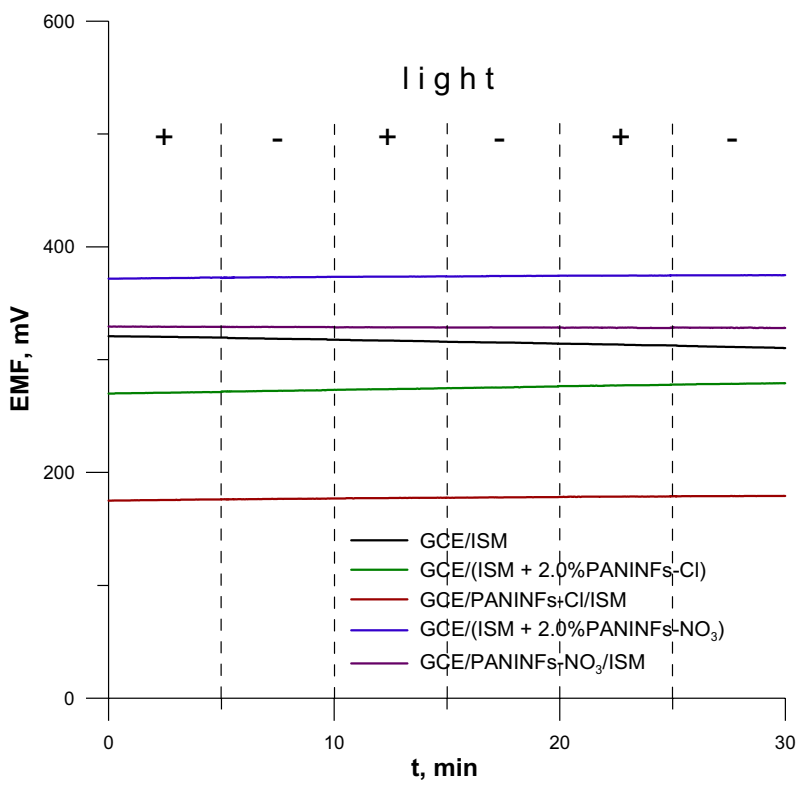

Fig. 9 Light sensitivity tests for chosen electrodes

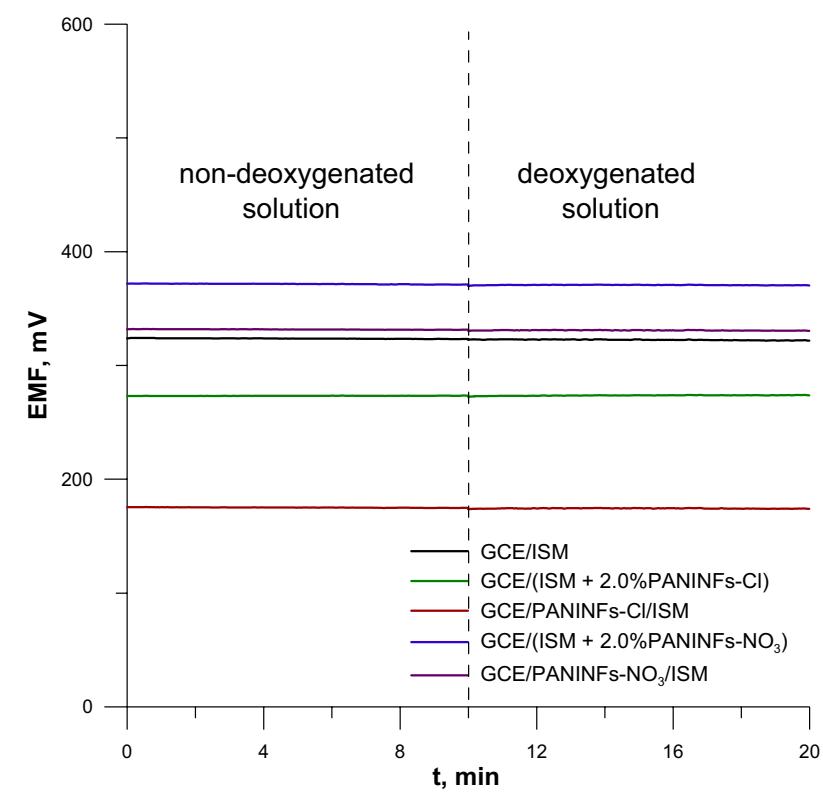

Fig. 10 Measurement of chosen electrodes potential in non-deoxygenated and deoxygenated solutions

be concluded that the tested electrodes are not sensitive to changes in the redox potential of the sample.

\section{Life time}

To establish the minimum time during which the electrodes are able to work properly, calibration curves were made in freshly prepared nitrate ions solutions regularly twice a week

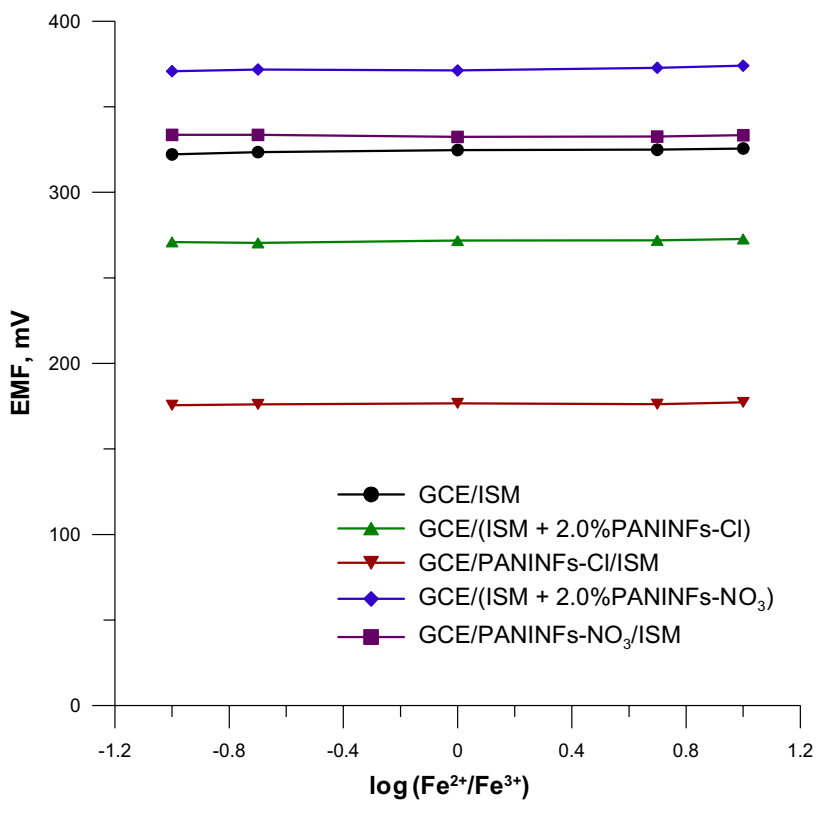

Fig. 11 Redox sensitivity tests for chosen electrodes

for 3 months. After this time, linear ranges of calibration curves unchanged and the slopes decreased slightly, while for all electrodes it was over $97 \%$ of the initial value. Therefore, it was found that the electrodes were still working properly, and their lifetime is at least 3 months.

\section{Electrochemical impedance spectroscopy}

To study the effect of electrode modification by use of PANINFs the electrochemical impedance spectroscopy measurements were conducted. This technique allows the determination of the membrane resistance and the tracking of the processes at the interface: the ion-selective membrane/the inner electrode. The obtained impedance spectra for PANINFs-Cl based electrodes and unmodified electrode are shown in Fig. 12. As seen in Fig. 12, all obtained impedance spectra showed the same shape, but in different size. They had high-frequency semicircle connected to the bulk resistance $\left(R_{b}\right)$ of the ion-selective membrane and its geometric capacitance $\left(C_{g}\right)$ (Horvai et al. 1986) and low frequency branch, which arose from the double layer capacitance and charge transfer resistance at the interface between polymeric membrane and the inner GCE electrode. The bulk membrane resistance $\left(R_{b}\right)$ determined from high frequency semicircle diameter was relatively low, even for unmodified electrode GCE/ISM due to presence in the membrane phase of ion-exchanger $\mathrm{TDMANO}_{3}$ in relatively high concentration. After membrane modification with the PANINFs addition, the resistance of the membranes decreased gradually as the content of nanofibers increased. A similar decrease in the membrane resistance was observed in the case of 


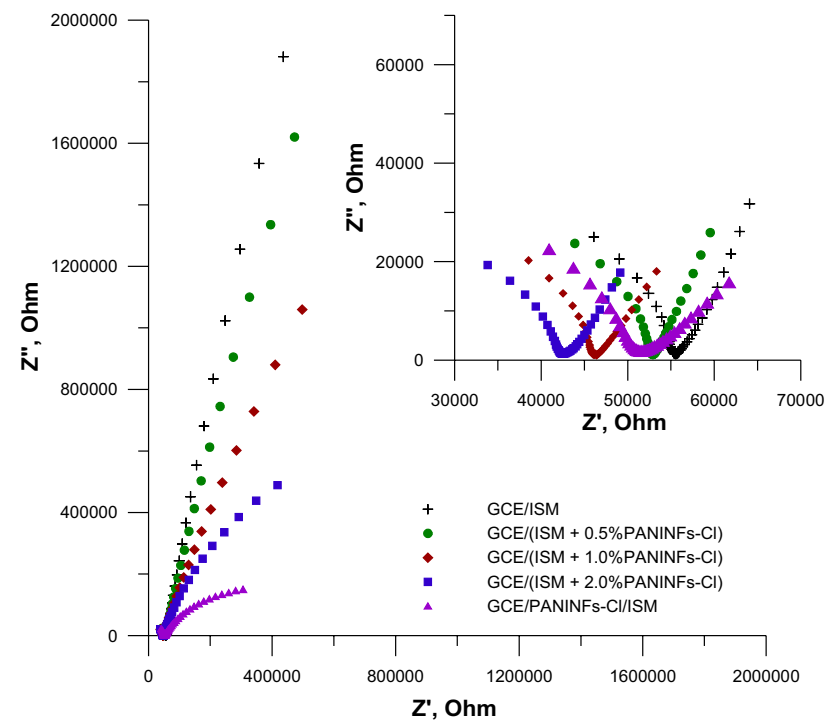

Fig. 12 Impedance spectra for GCE/ISM electrode and PANINFs-Cl based electrodes

electrodes in which the PANINFs were used as intermediate layer (Table 2).

Larger differences in the impedance spectra were observed in the low frequency range. As the content of nanofibers in the membrane increases, the low-frequency branch of the spectrum will decrease significantly, which is related to the increase in the double layer capacitance. The low frequency capacitance $C_{l f}$ determined from the low frequency limit on the basis on following dependence $C_{l f}=1 /\left(2 \pi f Z^{\prime}\right)$, where $f=0.1 \mathrm{~Hz}$ was $0.85 \mu \mathrm{F}$ for unmodified GCE/ISM electrode. The $C_{l f}$ value increased to the values of $1.1 ; 1.4$ and $3.0 \mu \mathrm{F}$ for electrodes GCE/ $(\mathrm{ISM}+0.5 \%$ PANINFs-Cl), GCE/(ISM $+1 \%$ PANINFs-Cl) and $\mathrm{GCE} /(\mathrm{ISM}+2 \% \mathrm{PANINFs-Cl}$ ), respectively. Of course, it was achieved due to the presence of nanofibers in the membrane. The greatest increase in capacitance to the value $11 \mu \mathrm{F}$ was observed for the electrode GCE/PANINFs-Cl/ ISM, in which nanofibers were used as an intermediate layer. Analogous results were obtained for electrodes modified with PANINFs- $\mathrm{NO}_{3}$. The obtained results clearly show that the use of PANI nanofibers in the construction of electrodes improves their electrical parameters, especially increasing the electrical capacity, thanks to which the transfer of the charge between the membrane and the internal electrode is facilitated and the electrodes show a stable and reproducible potential (Table 2).

\section{Analytical application}

Practical usefulness of PANINFs based electrodes was tested by determination of nitrates content in drinking water, river water and ground water samples. An important advantage
Table 2 Electric parameters of studied electrodes determined by EIS measurements

\begin{tabular}{|c|c|c|}
\hline Electrode & $\begin{array}{l}\text { Membrane } \\
\text { resistance } \\
{[\mathrm{k} \Omega]}\end{array}$ & $\begin{array}{l}\text { Low frequency } \\
\text { capacitance } \\
{[\mu \mathrm{F}]}\end{array}$ \\
\hline GCE/ISM & 87 & 0.85 \\
\hline GCE/(ISM+ 0.5\%PANINFs-Cl) & 79 & 1.1 \\
\hline GCE/(ISM + 1.0\%PANINFs-Cl) & 67 & 1.4 \\
\hline GCE/(ISM + 2.0\%PANINFs-Cl) & 64 & 3.0 \\
\hline GCE/PANINFs-Cl/ISM & 76 & 11 \\
\hline $\mathrm{GCE} /\left(\mathrm{ISM}+0.5 \%\right.$ PANINFs-NO $\left.{ }_{3}\right)$ & 80 & 1.0 \\
\hline $\mathrm{GCE} /\left(\mathrm{ISM}+1.0 \% \mathrm{PANINFs}-\mathrm{NO}_{3}\right)$ & 68 & 1.3 \\
\hline $\mathrm{GCE} /\left(\mathrm{ISM}+2.0 \% \mathrm{PANINFs}-\mathrm{NO}_{3}\right)$ & 62 & 1.4 \\
\hline GCE/PANINFs- $\mathrm{NO}_{3} / \mathrm{ISM}$ & 68 & 10 \\
\hline
\end{tabular}

of the potentiometric methods is the lack of necessity or only minimal sample preparation before the measurements. Therefore, water samples were analyzed as soon as collected using the calibration curve method. The only modification was the addition of $0.5 \mathrm{ml}$ of $1 \mathrm{~mol} \mathrm{~L}^{-1} \mathrm{Na}_{2} \mathrm{SO}_{4}$ solution to $50 \mathrm{ml}$ of the sample in order to ensure constant activity of the ions in the solution $\left(\mathrm{Na}_{2} \mathrm{SO}_{4}\right.$ as an ionic strength buffer). The obtained results are summarized in Table 3 , where it can be seen that there is a good agreement between the nitrate ions content determined with the proposed electrodes and the spectrophotometric method. This confirms that the obtained electrodes are a cheap and simple analytical device for nitrates monitoring in various water samples.

\section{Conclusions}

The successful usage of PANINFs for the construction of ion-selective electrodes is presented. It was found that the use of PANI nanofibers had a positive effect on the operation of potentiometric sensors. In particular, the stability and reversibility of the electrode potential has improved significantly. The electrodes modified with PANI-Cl nanofibers were characterized by a wider range of linearity of the calibration curves $\left(1 \times 10^{-6}-1 \times 10^{-1} \mathrm{~mol} \mathrm{~L}^{-1}\right)$ and lower limits of detection. Both kinds of sensors with PANINFs-Cl and PANINFs- $\mathrm{NO}_{3}$ as an intermediate layer were able to work in a wide range of $\mathrm{pH}$ (4.0-12.5) of solutions and under variable lighting conditions and the presence of gases $\left(\mathrm{O}_{2}\right)$ in the solution. The electrodes were used successfully for a period of 2 months and continued to function properly after that time. Obtained all-solid-state electrodes based on PANI nanofibers are suitable for nitrate monitoring in real water samples. Differences in the parameters of electrodes based on different PANI nanofibers result from differences in the microstructure of these nanofibers. The successful usage

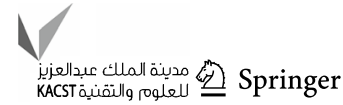


Table 3 Results of nitrate ions determination in real water samples by proposed electrodes and by spectrophotometry

\begin{tabular}{|c|c|c|c|c|}
\hline \multirow[t]{2}{*}{ Sample } & \multicolumn{4}{|c|}{ Nitrate ions content found $\left[\mathrm{mg} \mathrm{L}^{-1}\right]^{\mathrm{a}}$} \\
\hline & $\begin{array}{l}\mathrm{GCE} / \\
(\mathrm{ISM}+2.0 \% \mathrm{PAN}- \\
\text { INFs-Cl) }\end{array}$ & GCE/PANINFs-Cl/ISM & $\begin{array}{l}\text { GCE/PAN- } \\
\text { INFs-NO }_{3} / \mathrm{ISM}\end{array}$ & Spectrophotometry \\
\hline Drinking water & $5.35 \pm 0.02$ & $5.33 \pm 0.01$ & $5.31 \pm 0.02$ & $5.52 \pm 0.04$ \\
\hline River water & $16.23 \pm 0.03$ & $16.20 \pm 0.02$ & $16.11 \pm 0.02$ & $16.22 \pm 0.05$ \\
\hline Ground water & $23.22 \pm 0.03$ & $23.22 \pm 0.03$ & $23.20 \pm 0.03$ & $23.03 \pm 0.07$ \\
\hline
\end{tabular}

${ }^{a}$ Results are based on five measurements
PANINFs doped with chloride or nitrate ions the construction of nitrate ion-selective electrodes is presented.

Funding We acknowledge support from the Polish Ministry of Science and Higher Education.

Availability of data and materials Not applicable.

Code availability Not applicable.

\section{Declarations}

Conflict of interest On behalf of all authors, the corresponding author states that there is no conflict of interest.

Open Access This article is licensed under a Creative Commons Attribution 4.0 International License, which permits use, sharing, adaptation, distribution and reproduction in any medium or format, as long as you give appropriate credit to the original author(s) and the source, provide a link to the Creative Commons licence, and indicate if changes were made. The images or other third party material in this article are included in the article's Creative Commons licence, unless indicated otherwise in a credit line to the material. If material is not included in the article's Creative Commons licence and your intended use is not permitted by statutory regulation or exceeds the permitted use, you will need to obtain permission directly from the copyright holder. To view a copy of this licence, visit http://creativecommons.org/licenses/by/4.0/.

\section{References}

Abdolahi A, Hamzah E, Ibrahim Z, Hashim S (2012) Synthesis of uniform polyaniline nanofibers through interfacial polymerization. Materials 5:1487-1494. https://doi.org/10.3390/ma5081487

Ahmed HM, Ghali M, Zahra W, Ayad MM (2021) Preparation of carbon quantum dots/polyaniline nanocomposite: towards highly sensitive detection of picric acid. Spectrochim Acta Part A Mol Biomol Spectrosc 260:119967. https://doi.org/10.1016/j.saa.2021. 119967

An WH, Ark MP, Hung KC et al (2000) Enhanced electrochemical performance of poly (aniline) solid-contact $\mathrm{pH}$ electrodes based on alkyldibenzylamine. Anal Sci 16:1145-1149

Bakker E, Pretsch E, Bühlmann P (2000) Selectivity of potentiometric ion sensors. Anal Chem 72:1127-1133. https://doi.org/10.1021/ ac991146n
Bednarczyk K, Matysiak W, Tański T et al (2021) Effect of polyaniline content and protonating dopants on electroconductive composites. Sci Rep 11:1-11. https://doi.org/10.1038/s41598-021-86950-4

Bieg C, Fuchsberger K, Stelzle M (2017) Introduction to polymerbased solid-contact ion-selective electrodes-basic concepts, practical considerations, and current research topics. Anal Bioanal Chem 409:45-61

Bobacka J (2006) Conducting polymer-based solid-state ion-selective electrodes. Electroanalysis. https://doi.org/10.1002/elan.20050 3384

Bobacka J, Lewenstam A, Ivaska A (2001) Equilibrium potential of potentiometric ion sensors under steady-state current by using current-reversal chronopotentiometry. J Electroanal Chem 509:2730. https://doi.org/10.1016/S0022-0728(00)00515-5

Bobacka J, Ivaska A, Lewenstam A (2008) Potentiometric ion sensors. Chem Rev 108:329-351

Chumbimuni-Torres KY, Rubinova N, Radu A et al (2006) Solid contact potentiometric sensors for trace level measurements. Anal Chem 78:1318-1322. https://doi.org/10.1021/ac050749y

Crespo GA (2017) Recent advances in ion-selective membrane electrodes for in situ environmental water analysis. Electrochim Acta 245:1023-1034

Dan LI, Huang J, Kaner RB (2009) Polyaniline nanofibers: a unique polymer nanostructure for versatile applications. Acc Chem Res 42:135-145. https://doi.org/10.1021/ar800080n

Das P, Mondal S, Malik S (2021) Fully organic polyaniline nanotubes as electrode material for durable supercapacitor. J Energy Storage. https://doi.org/10.1016/j.est.2021.102662

De Marco R, Clarke G, Pejcic B (2007) Ion-selective electrode potentiometry in environmental analysis. Electroanalysis 19:1987-2001. https://doi.org/10.1002/elan.200703916

El-ghaffar MAA, Shaffei KA, Zikry AAF et al (2016) Novel conductive nano-composite ink based on poly aniline, silver nanoparticles and nitrocellulose. Egypt J Chem 4:429-443

Han WS, Chung KC, Kim MH et al (2004) A hydrogen ion-selective poly(aniline) solid contact electrode based on dibenzylpyrenemethylamine ionophore for highly acidic solutions. Anal Sci 20:1419-1422. https://doi.org/10.2116/analsci.20.1419

Horvai G, GráF E, TóTh K et al (1986) Plasticized poly(vinyl chloride) properties and characteristics of valinomycin electrodes. 1. High-frequency resistances and dielectric properties. Anal Chem 58:2735-2740. https://doi.org/10.1021/ac00126a034

Hu J, Stein A, Bühlmann P (2016) Rational design of all-solid-state ion-selective electrodes and reference electrodes. TrAC Trends Anal Chem 76:102-114

Huang J, Kaner RB (2004) A general chemical route to polyaniline nanofibers. J Am Chem Soc 126:851-855. https://doi.org/10.1021/ ja0371754

Jiang Y, Liu Z, Zeng G et al (2018) Polyaniline-based adsorbents for removal of hexavalent chromium from aqueous solution: a mini review. Environ Sci Pollut Res 25:6158-6174. https://doi.org/10. 1007/s11356-017-1188-3 
Konopka A, Sokalski T, Michalska A et al (2004) Factors affecting the potentiometric response of all-solid-state solvent polymeric membrane calcium-selective electrode for low-level measurements. Anal Chem 76:6410-6418. https://doi.org/10.1021/ac0492158

Lindfors T, Aarnio H, Ivaska A (2007) Potassium-selective electrodes with stable and geometrically well-defined internal solid contact based on nanoparticles of polyaniline and plasticized poly(vinyl chloride). Anal Chem 79:8571-8577. https://doi.org/10.1021/ ac071344b

Lindner E, Gyurcsányi RE (2009) Quality control criteria for solid-contact, solvent polymeric membrane ion-selective electrodes. J Solid State Electrochem. https://doi.org/10.1007/s10008-008-0608-1

Michalska A (2012) All-solid-state ion selective and all-solid-state reference electrodes. Electroanalysis 24:1253-1265. https://doi. org/10.1002/elan.201200059

Michalska A, Hulanicki A, Lewenstam A (1994) All solid-state hydrogen ion-selective electrode based on a conducting poly(pyrrole) solid contact. Analyst 119:2417-2420. https://doi.org/10.1039/ AN9941902417

Najim TS, Salim AJ (2017) Polyaniline nanofibers and nanocomposites: preparation, characterization, and application for $\mathrm{Cr}(\mathrm{VI})$ and phosphate ions removal from aqueous solution. Arab J Chem 10:S3459-S3467. https://doi.org/10.1016/j.arabjc.2014.02.008

Ocypa M, Michalska A, Maksymiuk K (2006) Accumulation of $\mathrm{Cu}$ (II) cations in poly(3,4-ethylenedioxythiophene) films doped by hexacyanoferrate anions and its application in $\mathrm{Cu} 2+-$ selective electrodes with PVC based membranes. Electrochim Acta 51:2298-2305. https://doi.org/10.1016/j.electacta.2005.03.080

Rubinova N, Chumbimuni-Torres K, Bakker E (2007) Solid-contact potentiometric polymer membrane microelectrodes for the detection of silver ions at the femtomole level. Sensors Actuators B Chem 121:135-141. https://doi.org/10.1016/j.snb.2006.09.007

Sutter J, Lindner E, Gyurcsányi RE, Pretsch E (2004) A polypyrrolebased solid-contact $\mathrm{Pb} 2+$-selective $\mathrm{PVC}$-membrane electrode with a nanomolar detection limit. Anal Bioanal Chem 380:7-14. https://doi.org/10.1007/s00216-004-2737-4
Vázquez M, Bobacka J, Ivaska A, Lewenstam A (2002) Influence of oxygen and carbon dioxide on the electrochemical stability of poly(3,4-ethylenedioxythiophene) used as ion-to-electron transducer in all-solid-state ion-selective electrodes. Sensors Actuators B Chem 82:7-13. https://doi.org/10.1016/S0925-4005(01) 00983-2

Zeng F, Qin Z, Liang B et al (2015) Polyaniline nanostructures tuning with oxidants in interfacial polymerization system. Prog Nat Sci Mater Int 25:512-519. https://doi.org/10.1016/j.pnsc.2015.10.002

Zeng X, Liu Y, Jiang X et al (2021) Improving the stability of Pb2+ ion-selective electrodes by using $3 \mathrm{D}$ polyaniline nanowire arrays as the inner solid-contact transducer. Electrochim Acta 384:138414. https://doi.org/10.1016/j.electacta.2021.138414

Zhang X, Manohar SK (2004) Polyaniline nanofibers: chemical synthesis using surfactants. Chem Commun. https://doi.org/10.1039/ b409309g

Zhang D, Wang Y (2006) Synthesis and applications of one-dimensional nano-structured polyaniline: an overview. Mater Sci Eng B Solid-State Mater Adv Technol 134:9-19. https://doi.org/10. 1016/j.mseb.2006.07.037

Zhang C, Li G, Peng H (2009) Large-scale synthesis of self-doped polyaniline nanofibers. Mater Lett 63:592-594. https://doi.org/ 10.1016/j.matlet.2008.11.041

Zhang T, Yue H, Gao X et al (2020) A novel electrode material of polyaniline nanowire array/three-dimensional hollow graphene ballsgraphene oxide for symmetric supercapacitor. Ionics 26:20632070. https://doi.org/10.1007/s11581-019-03360-3

Zhang Y, Tao Y, Wang K et al (2021) Two kinds of polyaniline fiber photo sensor with interdigital electrode and flexible hydrogel. J Appl Polym Sci 138:1-12. https://doi.org/10.1002/app.50628

Publisher's Note Springer Nature remains neutral with regard to jurisdictional claims in published maps and institutional affiliations. 